\section{Modelling the world, again}

\author{
David Spurgeon in Ottawa looks at two \\ recently published studies of the world's future
}

WHEN it was published in 1972, The Limits to Growth was a kind of landmark, crystallising in a mathematical model the views of those who believed that the world had come to a turning-point in its profligate use of resources, its growing pollution of the environment, and its inexorable population growth. Its message was basically a simple one: that if current trends continued, disaster was certain, because resources which were finite would soon be exhausted, pollution which was increasing would soon become intolerable, and the press of population which was exponential would soon outrun living space.

For many the book was authoritative because it was backed by computer studies-and perhaps because it reinforced existing fears or prejudices. But given its assumptions, its conclusions seemed rather obvious, and it provoked a rash of criticisms, as well as a number of similar studies. Whatever else may be said of it, though, it succeeded in raising the public's consciousness of some of mankind's major problems and prospects.

Two recently published studies* deal directly with the kinds of problem examined by The Limits to Growth: one, Catastrophe or New Society?, arose as a specific response to it, while the other, The Next 200 Years, could be said to have been undertaken in response to its underlying philosophy. Both disagree totally with the assumptions and conclusions of The Limits to Growth, while at the same time proceed from assumptions totally at odds with each other. What they have in common is a basic conclusion that the limits to growth-if any-are not physical, as suggested in The Limits to Growth, but sociopolitical, and that mankind is not doomed either to a no-growth economy or to disaster but is capable of providing a worthwhile and satisfying future for all. Where they differ is in how such a future could be brought about.

*Catastrophe or New Society? A Latin American World Model, Amilcar O. Herrera, Hugo D. Scolnik, Graciela Chichilnisky, Gilberto C. Gallopin, Jorge E. Hardoy, Diana Mosovich, Enrique Otieza, Gilda L. de Romero Brest, Carlos E. Suárez, and Luis Talavera (IDRC-064e; International Development Research Centre, Ottawa, Canada; 1976).

The Next 200 Years: A Scenario for America and the World, Herman Kahn, William Brown, and Leon Martel, with the assistance of the Hudson Institute (William Morrow and Company, Inc., New York; 1976).
The basic premise of The Next 200 Years is that what we need is not less growth, but more-and along pretty much the same lines as at present-at least until world-wide economic development has been completed. After that growth rates will slow and many economies will reach a more or less steady state. Catastrophe or New Society?, on the other hand, sees achievement of a good life for all, particularly those in developing countries, as impossible without certain fundamental changes in society. What is wrong with the arguments of Meadows and his ilk, in its view, is that they accept, "in a totally uncritical manner, the central values of society as it now is." Herrera and his colleagues maintain that the major problems facing society

are based on the uneven distribution of power, both between nations and within nations. The result is oppression and alienation, largely founded on exploitation. The deterioration of the physical environment is not an inevitable consequence of human progress, but the result of social organisations based largely on destructive values.

In its place must be constructed a new type of society-socialist, egalitarian, fully participatory, and nonconsumerist.

Both books project the future from a very clear ideological base, though the base is made more explicit and acknowledged more directly by Herrera's group than by Kahn's. Both are essentially utopian (Herrera's admittedly so, Kahn's not) and suffer from the basic fault of all such modelling of enormously complex systems: oversimplification, and the necessary exclusion of all sorts of potentially important variables that either cannot be accurately quantified or cannot be foreseen.

Kahn and colleagues argue that "the current malaise", as they call it, is propelled by a combination of compassion and guilt for the plight of the world's poor and the coincidental occurrence of world-wide crises in the supply of food and energy. They believe that the movement toward this view "has gone too far", and argue that there is both need and opportunity for economic growth-that precisely because America and the rest of the developed world use resources so intensely, there will be stimulation, not depression, of the economies of developing nations. Using what seems, as far as they reveal it, to be questionable data, the Kahn group suggests current population growth fears may be nothing much more than "an amusing episode in human history". Looking backward from 2176 , as they pretend to be able to do, they say "the temporary nature of the current population phenomenon becomes very obvious".

Similarly, energy supplies are no problem. Examining current fossil fuel reserves (on the basis of a 1973 US Geological Survey that has since been withdrawn by that agency and drastically revised downwards) and the prospects for other energy sources, both conventional and non-conventional, developed or not, the authors conclude:

Except for temporary fluctuations caused by bad luck or poor management, the world need not worry about energy shortages or costs in the future. And energy abundance is probably the world's best insurance that the entire human population (cven 15-20 billion) can be well cared for, at least physically, during many centuries to come.

The same goes for raw materials: “. . there is an abundance of raw materials for future generations as well as the present one, and ... the more man develops economically and technologically, the more there will be for all of humanity."

And as for food, "the position we argue is that, except for the occasional regional fluctuations caused by natural disaster, inappropriate policies or the misapplication of resources, the longterm prospect is for adequate food supplies". Within 200 years, the authors say, it will be possible to increase world food consumption to the level of the United States today. What will happen if "inappropriate policies or the misapplication of resources" continues to be the rule, as it is today, is not dealt with. Yet that, as the authors of the Latin American world model recognise, is precisely where the real problem lies.

To give them their due, the Kahn group do recognise this. They go so far as to state that

any limits to growth are more likely to arise from psychological, cultural or social limits to demand, or from incompetency, bad luck and/or monopolistic practices interfering with supply, rather than from fundamental physical limits on available resources.

What seems odd is their faith in things as they are, and their acceptance that they will continue that way.

Large income gaps between nations could persist for centuries ... there are few peasants, workers or even businessmen in developing nations who care much about gaps (whether arithmetic or geometric), no matter how much intellectuals, academics and some businessmen may profess to. The major objective of most people is to increase their own safety and improve their own standard of living and their own capabilities. When they make comparisons, it is 
usually with others at their socioeconomic level or with those who have recently been at their own or a lower level.

By such a yardstick, much of the Third World should have nothing to worry about. The Kahn group sees communist Asians with a GNP per capita of about $\$ 1,000$ by the year 2000 , and about half of the Third World with about double that. A desperately poor group, mostly in India but also in parts of Latin America and Africa, could-even with "reasonable" policies--attain only an average of about $\$ 200$ per capita by the year 2000. But in another hundred years almost all societies should have a GNP per capita of more than $\$ 2,000$. The fact that others may have 10 to 20 times more is, in their view, of no consequence.

The Latin American world model is based on the premise that, in the new society proposed, the production system has the satisfaction of basic human needs as a main objective. These needs are nutrition, housing, education and health. The mathematical model was constructed around the satisfaction of these needs, differentiated into five sectors: nutrition, education, housing, capital goods, and finally, consumer goods and other services. It was built to test the physical viability of the proposed society. This involved determining the period of time needed and the conditions under which the different regions could satisfy the basic needs to given levels.

The level of food was taken as 3,000 calories and 100 grams of protein per day $(3,200$ calories in advanced countries); of education, 12 years of basic education between the ages of 7 and 18; and of housing, one house per family. In the developed countries, the minimum dwelling would have an area of 70 square metres for an average family of 3.5 people, costing $\$ 4,900$ to build. For Africa and Asia, the standard house was more modest because of the current desperate housing situation: 7 square metres per person, at $\$ 23.40$ per square metre in Africa and $\$ 11.20$ in Asia. Housing conditions would reach developing country standards in 20 years.

The annual cost of education per student in underdeveloped countries reached a maximum of $\$ 150$, and an aggregated yield of 4 tonnes per hectare per year was assumed in agriculture. In developed regions, economic growth would be restricted to 1-2\% when GNP per capita exceeded $\$ 4,500$ annually. And for underdeveloped regions, once basic needs were satisfied, growth in GNP per capita had to be at least $2 \%$. This is to gradually reduce the gap between the developed and underdeveloped regions.

What did the model predict? For developed countries basic needs were shown to be satisfied in the first few years of the computer run (which ended in the year 2060). GNP per capita reached $\$ 9,470$ in that year (slightly less than Kahn's projection). Latin America could fulfill its basic needs in the early 1990s, and its GNP per capita would rise from $\$ 372$ in 1960 to $\$ 5,746$ in 2060 . Interestingly, the population growth rate, which was $2.8 \%$ in 1960 , decreased as general well-being improved, and was only $0.43 \%$ by 2060 , approaching stabilisation. The consequence for Latin America, then, is that it could satisfy its whole population's basic needs within a generation of the implementation of the proposed policies.

It would take Africa longer: that continent could satisfy its basic needs by 2008 . GNP per capita, $\$ 137$ in 1960 , would reach only $\$ 559$ in 2008 , and $\$ 2,657$ in the last year of the run. Thus if the policies proposed were applied, Africa could satisfy the basic needs of its population with 30 years after 1980, according to the model.

Asia's position is very different. According to the model, basic needs could not be satisfied by 2060. Food consumption of 2800 calories could be achieved by 1992; that level would be maintained until the mid-2020s, but would decline after that until levels reached were incompatible with survival. Nor were housing needs achieved, with only 0.82 house for every family in 2040. Education would be the only basic need totally satisfied by 2040 .

"The problem in Asia arises in the food sector," says the report. "By 2010 , all available land is being cultivated. Thereafter, economic effort in the sector is devoted to increasing livestock and fisheries. This, however, is not enough to feed the growing population adequately". If agricultural yields were increased from 4 to 6 tonnes per hectare, however, basic needs could be satisfied. GNP per inhabitant- $\$ 89.70$ in 1960-reaches $\$ 1,516$ in 2060. But food remains a problem, for in the mid-2030s the remaining land has been used, and "it is inevitable that some years after 2060 Asia will not be able to feed its inhabitants adequately."

Finally, a run was carried out to test the effect of cessation of technological progress in the evolution of the regions involved. It was supposed that there would be no more technological progress after the year 2000 . This produced significant effects. In Latin America, it increased the time necessary to satisfy basic needs, increased the population growth rate, and reduced GNP per capita (from $\$ 5,746$ in 2060 to $\$ 1,173$ ). In Africa, as in Asia, minimum objectives could not even be achieved: the economic system collapsed. Only

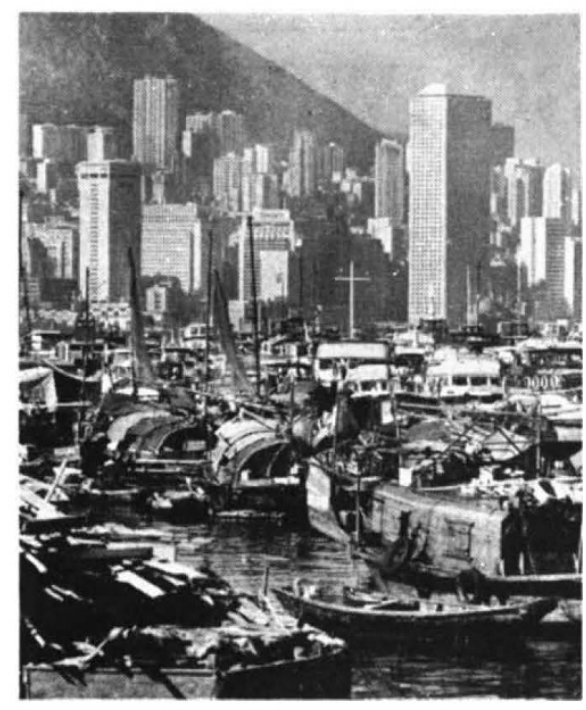

Two views of the limits to growth?

food reached the target level in Africa, and then only for a brief period. In Asia, none of the basic needs were met. Thus technological progress is seen as essential for liberation from underdevelopment and misery.

International aid is not seen by either the Kahn or the Herrera study to be a decisive factor in raising the level of well-being of Third World countries. Under conditions currently prevailing, even increased international aid would only contribute to increased spending by privileged sectors and have little or no effect on the living standards of the majority of the people. In direct contrast to the Kahn hypothesis, Herrera and his colleagues maintain that economic growth without concurrent drastic modification in income distribution would not achieve an adequate level of well-being for the entire populations of developing countries.

Many people tend to argue that studies like these are nothing more than a form of wish fulfillment; that they will increase the skepticism of laymen ignorant of the true nature of future studies and mathematical modelling because they seem to indicate that computer studies can be used to prove any thesis their authors wish; that their obvious political naiveté or ideological bias makes them trivial, if not dangerous. Others will see them as useful contributions to a continuing debate-a debate that must be kept going if solutions are to be found for the problems they deal with. Perhaps they will have done all they can if they succeed in showing, as both studies are intended to do, in the words of the Herrera group, "that the fate of man does not depend, in the last instance, on insurmountable physical barriers but on social and political factors that man must modify." 